\title{
Editor's Letter
}

Dearest,

Horticultura Brasileira 30 (3) is already in your hands, and on your screen! In our cover article, our editor, Carlos Alberto Lopes, one of the most respected researchers among us, weaves relevant considerations on plant diseases, their control and organic agriculture. Don't wait, read it straight away!

We are pleased to inform that our online system for paper submission is already active. To access it, go to www.horticulturabrasileira.com.br/editor. It is a very friendly system. On first access, create a username and password, and start surfing. However, if there is need, there are tutorials at www.hidroplan.com.br/cursos_seer.php, Electronic System for Journal Publishing. The online system will concentrate all communication between authors and the editorial board, including editors and peer reviewers. The online system will speed up the reviewing process and will allow authors to keep track of it. We received our first online submission on July 10 and up to August 31, we already counted 30 other. Our thanks to our mate João Bosco Carvalho da Silva who helped Horticultura Brasileira to score this goal.

Those who had their papers accepted for peer reviewing prior to the operation of the online system, should not worry. These papers will go on normally. Papers submitted but still under pre-analysis are being evaluated and, upon acceptance to peer reviewing, will be returned to authors to be submitted electronically straight to the reviewing process.

If there are doubts or any difficulty in using the online system, our office is ready to help.

Until the next issue,

Paulo Melo

Editor in chief 